our predecessors have already done this. The future requires that we, in our time, show an equal sensitivity to the needs of medical progress and, by avoiding the imposition upon medicine of a rigidity of training and an inelastic career structure, remain free to take advantage of opportunities and to meet needs as they arise.

These dangers are most evident in those clinical specialties whose practice, as defined at present, requires a high degree of manual skill. Over the last seventy years, antisepsis, asepsis, and anaesthesia have enabled such specialties to conquer a considerable number of their problems. But it is evident that the many which remain, and pose the present challenge, are unlikely to be susceptible to the same approach. Yet in such specialties the systems of training and requirements for staff appointments are predominantly determined by previous achievements, and these militate against the recruitment of those who, by bringing other skills to bear, could help to solve the problems which prevent progress. The incorporation within the specialty of a few men who were allowed to limit the field of their clinical responsibility so that they might acquire the requisite skill in those ideas and techniques of which the subject stands in such need, might go far to solve the present dilemma.

These are no new prescriptions. They are the modern version of the principle on which Linacre founded his College; that our profession should contain men who are not only deeply studied in physic but groundedly learned. Before the first world war these requirements were accepted as in the highest tradition of British medicine, and among the chief ornaments of our profession at that time were clinicians who were also outstanding as pathologists or physiologists or chemists. In recent years, however, overwhelmed with the flood of new knowledge, we have seemed to lose sight of this principle. To our failure in this respect we can primarily attribute the present increasing separation of practice from research, the widening division between the components of medical knowledge and the disappointing progress of many specialties. The most urgent task before medicine to-day is to redress our omission while this is still possible.

There remains one final consideration.

\section{The Essential Endeavour}

In the advancement of knowledge, associations of men bringing together a wide variety of talents and experience have played a major part. Here men make contact with other interests and are exposed to a wider perspective which enables them to appreciate the relationships of their own specialized preoccupations to the general body of learning. Here they see excellence and are prompted to emulation. But, above all, it is in such associations that men become conscious of a continuing and underlying community of interest which strengthens each against intellectual isolation and preserves the body of their learning from dissolution. That is the principle underlying the concept of a university. That was the principle underlying Linacre's great design. But to-day, with the increasing extension of the field of medicine and the differentiation which has been allowed to creep into its professional structure, it is a principle that is becoming increasingly difficult to realize.

Yet if medicine is not to disintegrate into a series of isolated specialties and its organization into a collection of bodies representing simply sectional concerns, then its traditional institutions must ensure, as they have done in the past, that they remain the focus of its manifold interests. This they can do only if they succeed in sustaining a sense of common fellowship among the many varieties of men whose services are now necessary to medicine. The essential endeavour of Thomas Linacre and his contemporaries was directed towards realizing this ideal. It remains for us, their successors, to continue in the context of our own times the endeavour that they began; for it is only by the unremitting efforts of its members that a profession can remain within reach of those ideals on which its continued existence as a living and operative force ultimately depends.

\section{ACUTE PERFORATED PEPTIC ULCER FREQUENCY AND INCIDENCE IN THE WEST OF SCOTLAND}

BY

\author{
R. A. JAMIESON, F.R.C.S.Ed.
}

(From the Department of Surgery, University of Glasgow)

A survey of perforated peptic ulcer in the West of Scotland for the period $1924-43$ has already been published (Illingworth, Scott, and Jamieson, 1944 ; Jamieson, 1947). The present report brings the survey up to date by covering the period 1944-53.

The region surveyed includes the City of Glasgow and the counties of Argyll, Dumbarton, Lanark, and Renfrew. This region is particularly suitable for a survey of the kind, because it carries a community which is large and (as regards emergency surgery) virtually isolated. The population exceeds 2 million, densely congregated towards the centre in Glasgow and the industrial towns of Clydeside. Towards the periphery of the region the population is sparse, and its few cases of perforation are directed towards Glasgow. It follows that the population from which patients are drawn corresponds with the population of the four counties, and can be determined from the decennial census and from the annual estimates of population made by the RegistrarGeneral. Finally, a count of the perforations occurring in this community can be made by searching the hospital records, for the features of perforation are so characteristic and the need for hospital treatment so clamant that few who have perforated can fail to reach hospital.

In comparing present with previous hospital experience account must be taken of the increasing amount of emergency surgery done at the old municipal and local hospitals taken over in 1948 by the State. It is no longer possible to estimate the total perforations in the region from a count of those treated in the large teaching hospitals in Glasgow. Formerly, as we showed in the previous survey, these institutions treated $80 \%$ of the perforations in the region, but now the proportion has fallen to $65 \%$. A change of this kind was foreseen, and in the present survey perforations have been counted for each hospital in the region for each year. The total count for 10 years amounts to 6,343 perforations.

The patients counted in the present and previous surveys are limited to those in whom the diagnosis of perforation has been confirmed at laparotomy or necropsy. The standard operative treatment has been by simple closure of the perforation. Gastro-enterostomy has been added 244 times. Primary gastrectomy has been done 26 times.

\section{Frequency and Incidence of Perforation in the Population}

The number of perforations treated annually in the region is shown in Fig. 1. It will be seen that over the 30-year period perforation has become increasingly common. The general trend is an almost linear increase from some 200 perforations in 1924 to some 700 in 1953. Apart from the violent disturbance of the uniform trend during the war years, which was discussed in the previous report, the yearto-year fluctuations have been small.

These figures provide a basis for calculating the changing incidence of perforation in a population of known size. According to the Registrar-General's estimates the population has remained almost stable at about 2.1 million, and it follows that the curves shown in Fig. 1 represent incidence 
rates per 2.1 million. In more convenient units, the incidence of perforation per 100,000 population in sample years was: 11 (1924), 19 (1930), 30 (1940, a war year of high incidence), 31 (1950), and 33 (1953).

\section{Sex and Age Distribution}

The great preponderance of males remains a feature, but the preponderance is now less than it used to be (Fig. 1). During the period 1924-43 the ratio was 19 males to 1 female, and during 1944-53 it was only 12 to 1. A falling sex ratio was already apparent towards the end of the previous survey, and a gradual fall seems to be continuing.

The general features of the age distribution are shown in Fig. 2. The great majority of the patients fall into the middle-age groups. Elderly patients are not numerous, but they are of special importance because perforation carries a high fatality rate in old age : it will be seen that the group of elderly patients, small though it is, includes among its members one-third of all the patients in the series who died. Women who perforate tend to be older than men, and in the previous survey there was a material difference in mean age ( $3.0 \pm 0.78$ years). A difference is again found in the present survey $(1.36 \pm 0.75$ years $)$, but it is smaller than before, and barely reaches the conventional level of significance. It is of interest to note that between the two surveys the mean age at perforation has increased, in women very slightly (from 43.9 to 44.2 years) and in men materially (from 40.9 to 42.9 years). These changes are of the kind expected, for we noted previously that the age of perforation had been rising throughout the period 1924-43.

\section{Incidence of Perforation at Various Ages}

The changes in mean age at perforation noted above may appear small, but they have a striking effect on the incidence of perforation calculated on the basis of the population alive at successive ages, for the population dies out rapidly as age advances. The incidence of perforation at various ages, calculated as at the census years 1931 and 1951, is shown in Fig. 3. It will be seen that at every age group the incidence of perforation has risen with the lapse of 20 years. The increases are not uniform. The increase is small at the younger ages, greater in middle age, and more than doubled at ages over 60 . Ageing of the population cannot, however, be invoked to explain the changes discussed here, where the incidence rates are calculated on the basis of 100,000

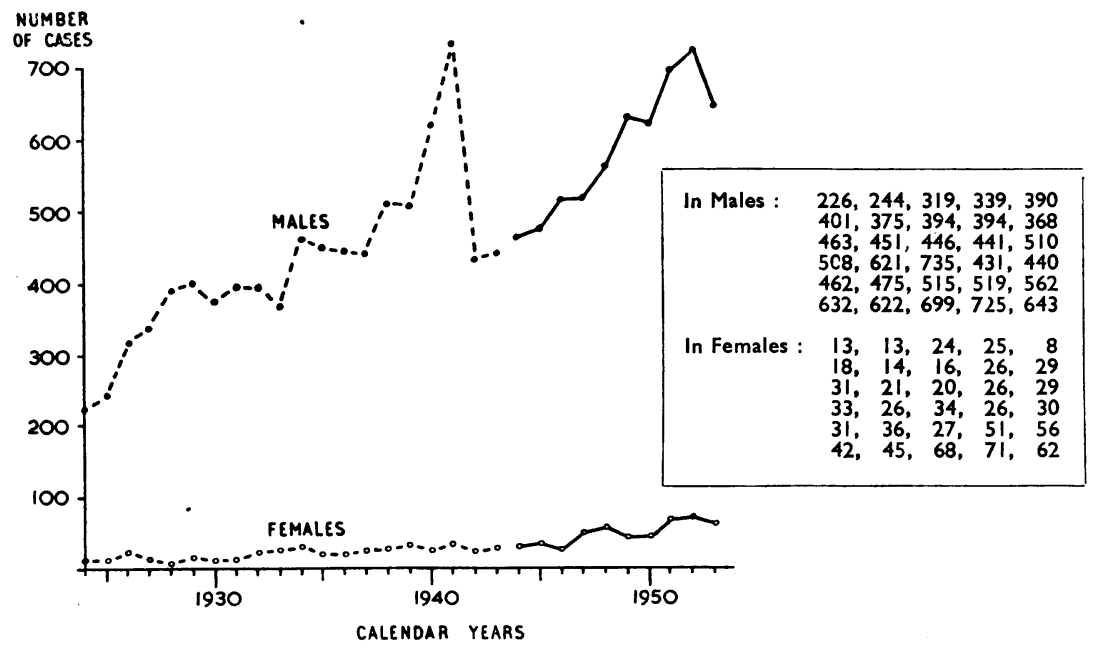

Fig. 1.- Number of perforations in successive years from 1924-53. The numbers given for 1924-43 are estimates based on counts at teaching hospitals (see text), and the numbers for 1944-53 are actual counts at all hospitals. The broken lines represent previous survey, the continuous lines the present survey.

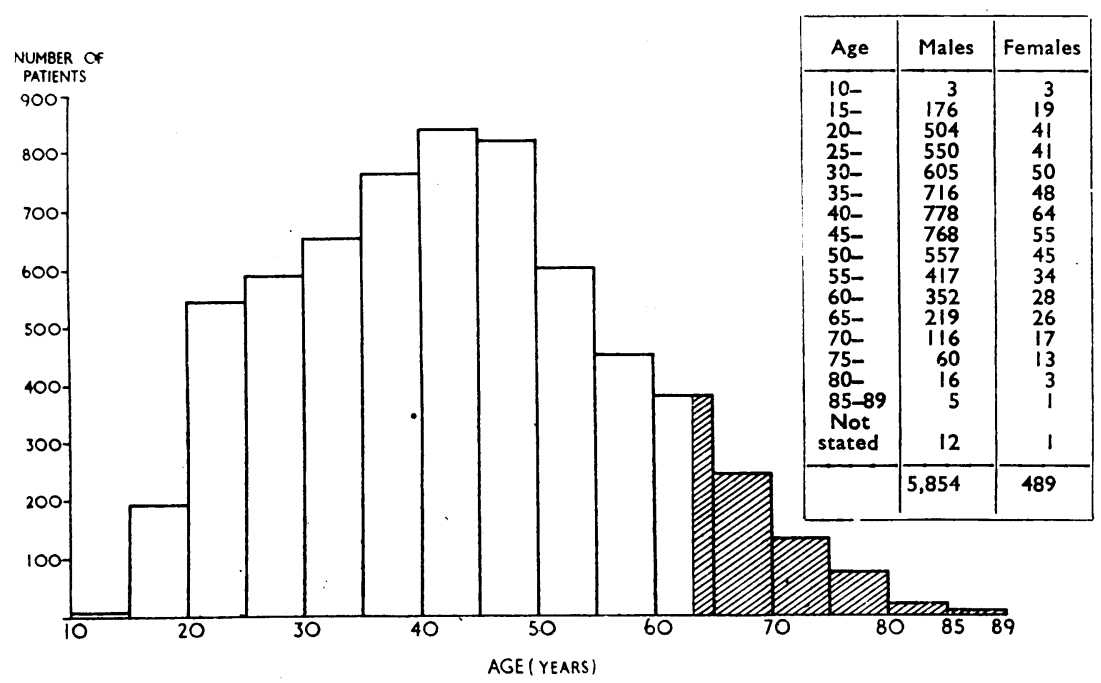

FIG. 2.-Graph showing age distribution for males and females together. Patients over 63 yield one-third of all deaths. For data on deaths see Fig. 8.

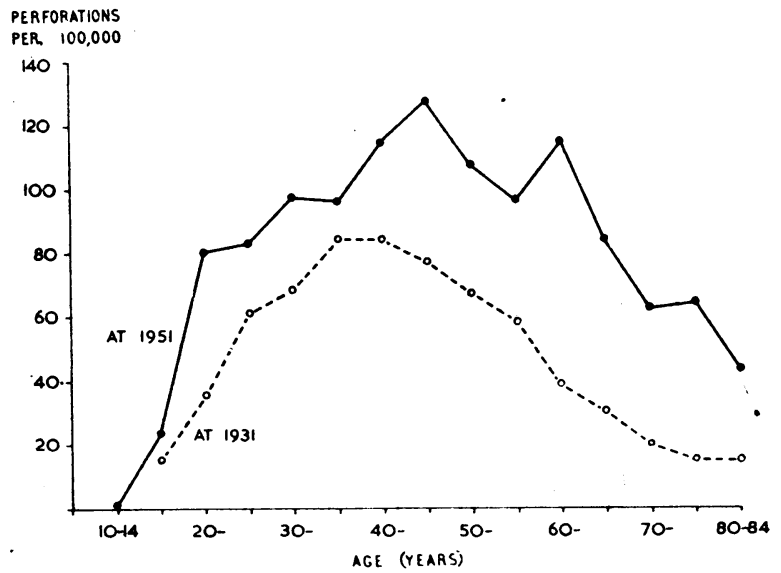

\begin{tabular}{|c|c|c|}
\hline Age & 1931 & 1951 \\
\hline $5-$ & - & - \\
$10-$ & $\overline{1}$ & 1 \\
$15-$ & 15 & 23 \\
$20-$ & 35 & 80 \\
$25-$ & 61 & 83 \\
$30-$ & 68 & 97 \\
$35-$ & 84 & 96. \\
$40-$ & 84 & 114 \\
$45-$ & 77 & 127 \\
$50-$ & 67 & 107 \\
$55-$ & 58 & 96 \\
$60-$ & 39 & 104 \\
$65-$ & 30 & 84 \\
$70-$ & 20 & 62 \\
$75-$ & 15 & 64 \\
$80-$ & 15 & 64 \\
$85-89$ & - & - \\
\hline
\end{tabular}

Fig. 3.-Annual incidence in males per 100,000 males living at each 5-year age grcup. Based on censuses of 1931 and 1951, and the perforations of 1930, 1931, 1932 and 1950, 


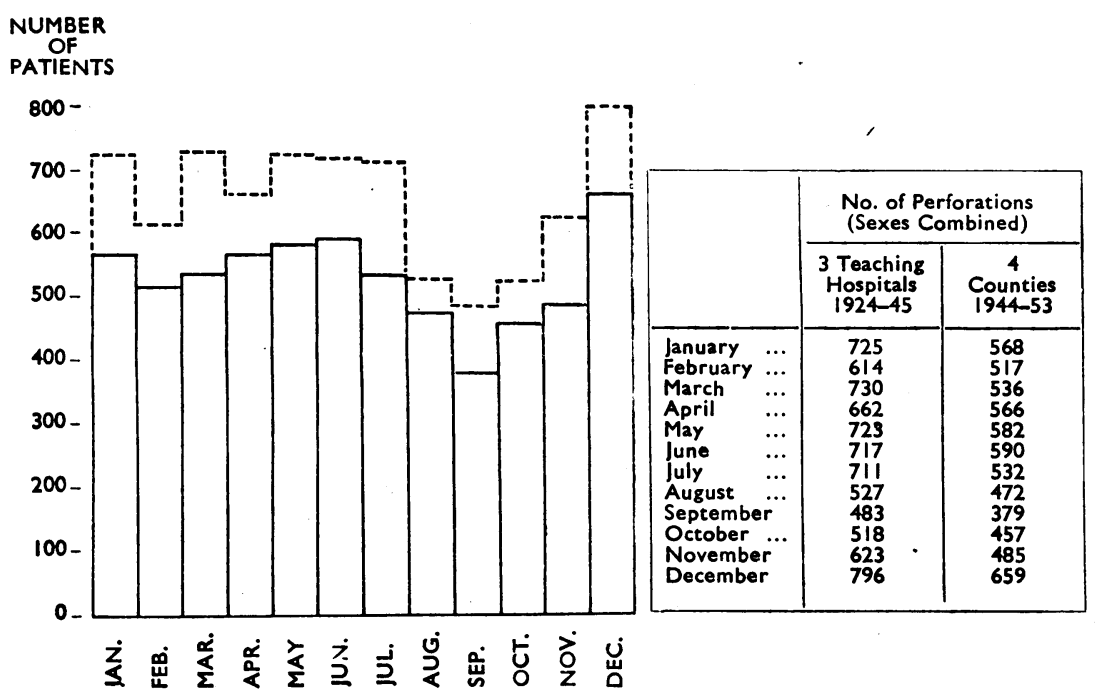

Fig. 4.-Incidence by months. The broken line represents previous survey, the continuous line the present survey.

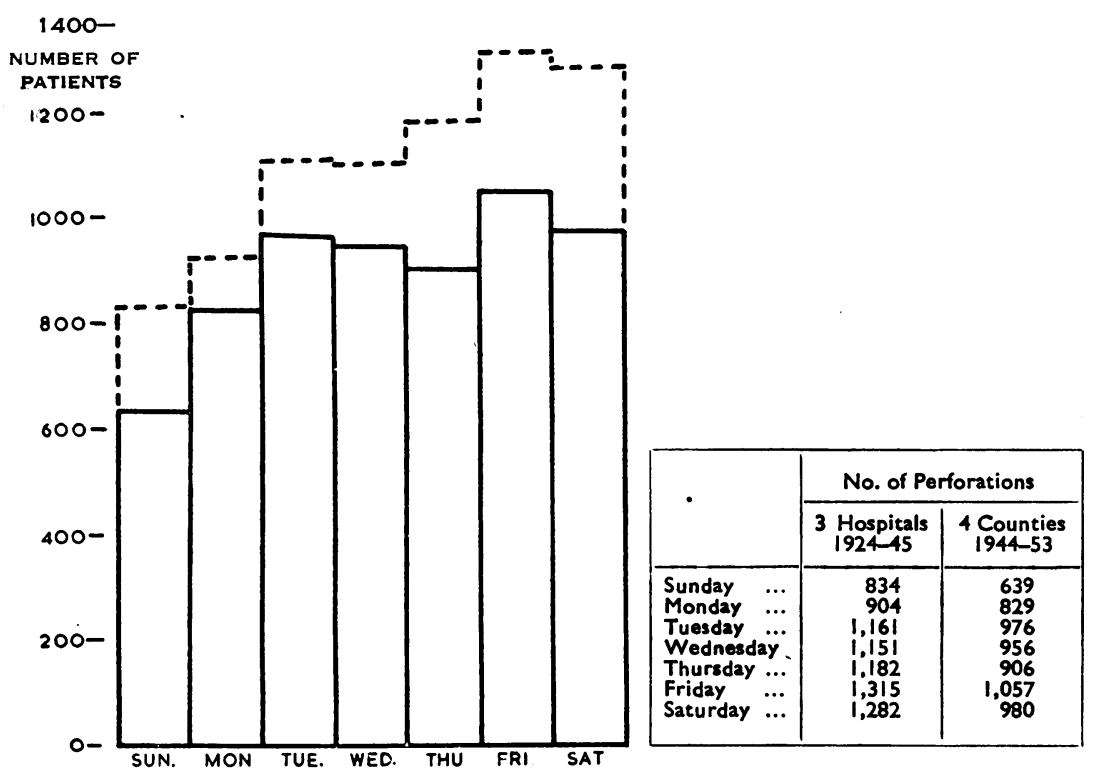

FiG. 5.-Incidence by days of the week. The broken line represents previous survey, the continuous line the present survey.

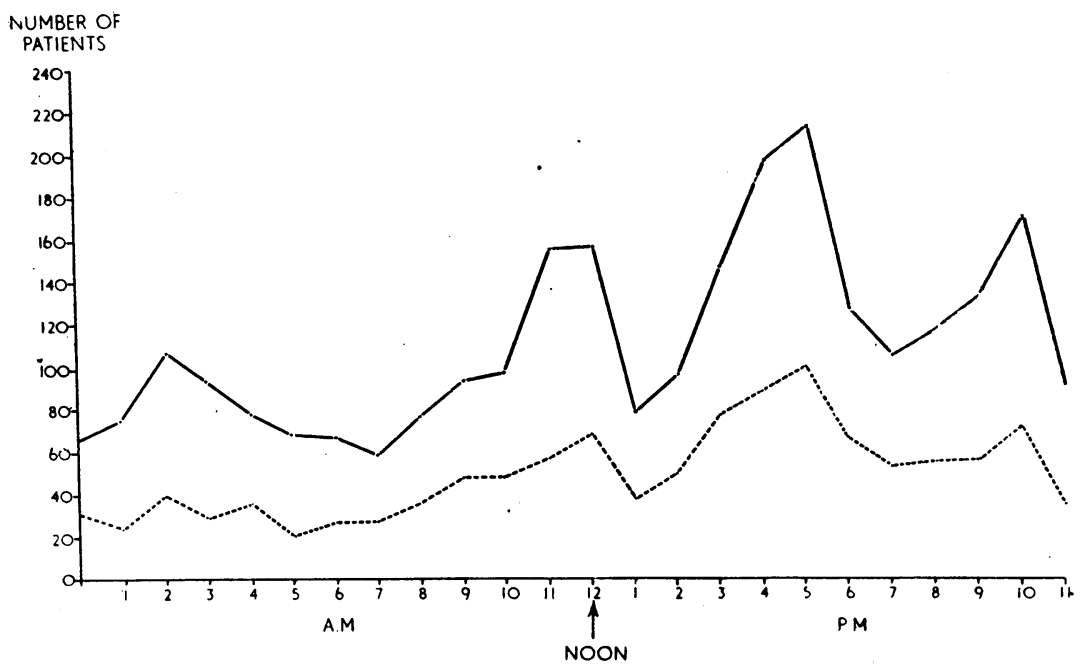

FIG. 6.-Broken line represents previous survey; continuous line, the present survey. population alive at each age group. The increasing incidence of perforation in the elderly need not be regarded with gloom. It is attractive to speculate that ulcer patients (from whom the victims of perforation are recruited) are surviving into old age in larger numbers now than previously.

It is of interest to attempt an estimate of the risk of perforation in ulcer patients, and to compare this with the risk of reperforation among those who have already perforated once. At the rates operating in 1951 there was approximately 1 perforation annually per 1,000 adult males (96 male perforations per 100,000 males aged 20 or more). According to the field survey of Doll and Jones (1951), the incidence of ulcer in the adult male population is between 50 and 100 per thousand. Taken in conjunction, these estimates suggest that, among adult males with ulcer, between 1 and $2 \%$ perforate annually. This figure can be compared with the risk of reperforation. In a follow-up study of patients who perforated between 1938 and 1943 (Illingworth, Scott, and Jamieson, 1946) the annual risk of reperforation within the first five years varied between 1.4 and $2.4 \%$. It appears that among the survivors of perforation the risk of reperforating is about the same as the risk of perforation in the ulcer population at large. This conclusion is advanced with some diffidence, because it is at variance with general opinion.

\section{Incidence of Perforation by Months of the Year}

Cases occurring in like months over the ten-year period have been added together. Fig. 4 shows the monthly distribution so obtained, and compares it with the distribution over the previous 20 years. The two distribu-

\begin{tabular}{|c|c|c|}
\hline & $\begin{array}{c}\text { Hour of } \\
\text { Perforation }\end{array}$ & \multicolumn{2}{|c|}{\begin{tabular}{c} 
No. of Perforations \\
\cline { 2 - 3 }
\end{tabular}} & $\begin{array}{c}\text { 1 Hospital } \\
1938-45\end{array}$ & $\begin{array}{c}4 \text { Counties } \\
1944-53\end{array}$ \\
\hline $\begin{array}{c}\text { Midnight- } \\
\text { I a.m.- }\end{array}$ & 30 & 67 \\
2 a.m.- & 25 & 73 \\
3 a.m.- & 40 & 109 \\
4 a.m.- & 27 & 93 \\
5 a.m.- & 34 & 78 \\
6 a.m.- & 20 & 64 \\
7 a.m.- & 26 & 63 \\
8 a.m.- & 27 & 58 \\
9 a.m.- & 36 & 76 \\
10 a.m.- & 49 & 92 \\
11 a.m.- & 47 & 98 \\
Noon- & 57 & 154 \\
1 p.m.- & 68 & 156 \\
2 p.m.- & 36 & 97 \\
3 p.m.- & 49 & 116 \\
4 p.m.- & 75 & 168 \\
5 p.m.- & 88 & 219 \\
6 p.m.- & 99 & 231 \\
7 p.m. & 65 & 147 \\
8 p.m.- & 54 & 126 \\
9 p.m.- & 55 & 138 \\
10 p.m.- & 56 & 153 \\
11 p.m.- & 71 & 170 \\
\hline Not stated & 35 & 110 \\
\hline & 179 & 1,350 \\
\hline & 1,348 & 4,206 \\
\hline & & \\
\hline
\end{tabular}


tions are very similar. Allowing for the varying length of calendar months, the incidence of perforation is about uniform from January to July. The incidence falls during August, September, and October, and returns to about the spring level in November. December shows an incidence higher than any other month. It need hardly be said that these fluctuations in numbers are much too large to be readily attributed to chance. It is relevant to point out that the holiday month in the West of Scotland is July, and it seems possible that the relative deficiency of perforation in the ensuing three months may perhaps be due to the July period of rest and recreation. The high incidence of perforation in December is not limited to the Christmas period, but is spread over the second half of the month. Many of the artisan class work overtime in the week or two before Christmas in order to earn extra wages to cover the Christmas expenses, and it may be that the high incidence of perforation in December is in part attributable to fatigue rather than to dietary indiscretion.

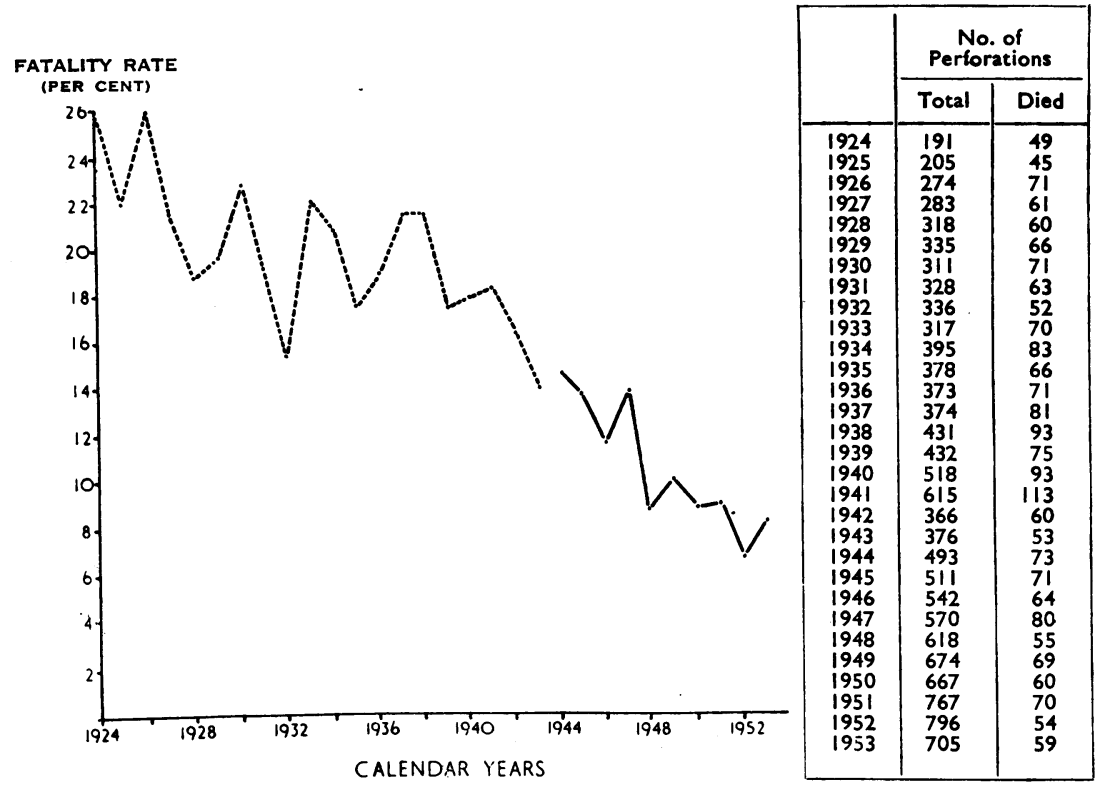

Fig. 7.-Fatality rates by calendar years. Data for 1924-43 are for three teaching hospitals and for 1944-53 for all hospitals in four counties. The broken line represents the previous survey, the continuous line the present survey.

\section{Perforation by. Days of the Week \\ In a similar way, perforations occur- ring on like days of the week have been added together, and the results are shown in Fig. 5. Again there is close agreement between the distributions obtained in this and the previous surveys. Perfora- tion is least com- mon on Sundays, commoner on Mondays, and commoner still}

Incidence of FATALITY RATE during the remainder of the week, reaching a maximum incidence on Fridays. The departure from uniformity of distribution is large, and the Friday perforations exceed the Sunday perforations in the ratio of about $3: 2$.

Variation of the frequency of perforation according to days of the week was sought in the first instance because the week-end rest provided an opportunity for testing the thesis that incidence is related to periods of rest and fatigue. It will be seen that the findings are compatible with this thesis.

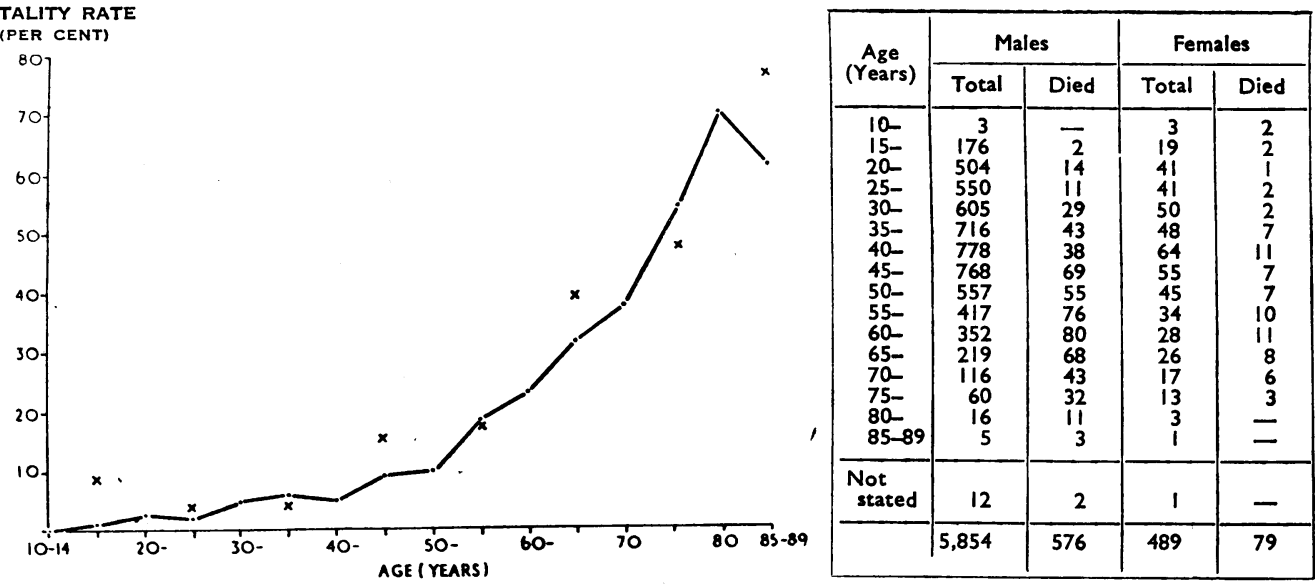

Fig. 8.-Fatality rates by age for males and females. Perforations, 4 counties, 1944-53. Continuous line represents males, the crosses females.

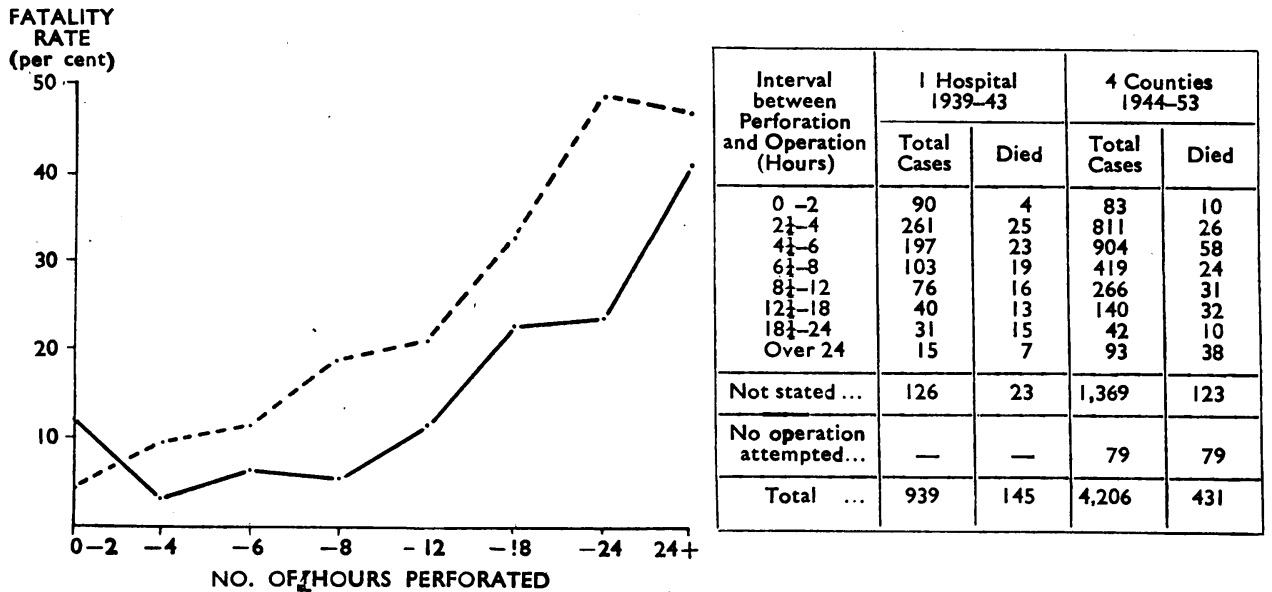

FIG. 9.-Deaths by delay in operation. The broken line represents the previous survey, the continuous line the present survey. 


\section{Incidence of Perforation by Hours of the Day}

Perforation of a peptic ulcer is so sudden and so painful that the moment of perforation can nearly always be determined, though unfortunately it is not always recorded. In a search of 4,206 case records the hour of perforation was obtained in 2,856, and the findings are shown in Fig. 6 . It will be seen that perforation is relatively uncommon during the night, increases in frequency to a minor peak at the end of the morning, to a major peak at the end of the afternoon, and again to a minor peak in the late evening. There is a sharp drop in incidence at noon and at 5 p.m., which for most of the population mark the lunch break and the end of the working day respectively.

The variation in the frequency of perforation according to the hours of the day is in harmony with the general thesis that incidence varies with periods of rest and fatigue.

\section{Relative Incidence of Perforation at Different Sites}

The site of a perforation is easily defined as gastric or duodenal when it lies well proximal to the pylorus or well beyond it. When the perforation is close to the pylorus, the pylorus itself becomes obscured by oedema and it may be impossible to say on which side of it the perforation lies; such ulcers usually prove on subsequent laparotomy to be duodenal, and they are here classed along with the duodenal perforations in a group termed pyloro-duodenal. Finally, there is a group termed "site not stated," which includes patients whose detailed case records were not available, and about whom information was obtained from theatre log-books, hospital registers, and the like.

According to these conventions of nomenclature the site of perforation was as shown in Table $\mathrm{I}$.

TABLE'I

\begin{tabular}{|c|c|c|c|c|}
\hline & & Males & Females & Total \\
\hline $\begin{array}{lll}\text { Gastric } & \ldots & \ldots \\
\text { Pyloro-duodenal } & & \ldots \\
\text { Stomal } & & \ldots \\
\text { In a Meckel's diverticulum } \\
\text { Oesophageal } & \ldots & \ldots \\
\text { Site not stated } & \ldots & \ldots\end{array}$ & $\begin{array}{l}\cdots \\
\cdots \\
\cdots \\
\cdots\end{array}$ & $\begin{array}{r}248 \\
5,125 \\
87 \\
4 \\
1 \\
389\end{array}$ & $\begin{array}{r}71 \\
378 \\
3 \\
- \\
37\end{array}$ & $\begin{array}{r}319 \\
5,503 \\
90 \\
4 \\
1 \\
426\end{array}$ \\
\hline & & 5,854 & 489 & 6,343 \\
\hline
\end{tabular}

It will be seen that pyloro-duodenal perforations far exceeded all other types, and accounted for some $87 \%$ of the total. Gastric perforations accounted for only $5 \%$ of the total. Of the 90 examples of stomal perforation, 2 followed the Aylett operation, 13 followed gastrectomy, and the remaining 75 were presumed to follow gastroenterostomy (61 were stated to do so and in 14 no comment was made). The perforations in Meckel's diverticula were verified to lie beside ectopic "gastric" epithelium, and were believed to result from peptic ulceration; all occurred in youths aged 10-19.

The ratio of pyloro-duodenal to gastric perforation is very different in the two sexes. In males the pyloroduodenal/gastric ratio is $21: 1$. In females it is $5: 1$. The accuracy of these ratios should not be much disturbed by leaving out of consideration the composition of the group in whom the site of perforation is not stated; it will be recalled that in this group the detailed case records were not available, and there is no reason to suppose that this was in any way correlated with the site of perforation.

\section{Deaths from Perforation}

The fatality rate from perforation was noted to be falling throughout the period $1924-43$, and the fall has continued throughout the period 1944-53. The fatality rates for the 30-year period are shown in Fig. 7. If year-to-year fluctuations are ignored the general trend appears to be linear, without any sudden improvement which might correspond in timing with the introduction of new therapeutic agents such as the sulphonamides, penicillin, or the muscle relaxants. The improvement over the 30 -year period is quite remarkable - the fatality rate falls from about $25 \%$ to about $8 \%$-and it must be remembered that this improvement has taken place despite an increasing proportion of elderly patients suffering perforation.

There are doubtless many factors which influence the outcome in individual patients. All that is attempted here is to draw attention to a few factors of general importancenamely, the age and sex of the patient, the site of the ulcer, the interval that elapses between perforation and operation, and the season of the year.

\section{Deaths by Age Groups in Males and Females}

The fatality rate in males and females at different ages is shown in Fig. 8. Males have been taken in five-year groups ; females, owing to their small number, in 10-year groups.

It will be seen that the fatality rate not only increases with age but increases more and more steeply as age advances. The fatality rate is less than $5 \%$ up to about age 35 , rises to $10 \%$ by age $50,20 \%$ by $60,40 \%$ by 70 , and $70 \%$ by 80 . It will be seen also that fatality rates are about the same in males and females at equivalent ages. These figures, which represent the overall fatality rates for the period 1944-53, differ in two respects from the corresponding fatality rates for the period 1924-43 : first, the fatality rates are now much lower for every age group : and second, the fatality rates (at equivalent ages) are now no longer higher in females than in males.

\section{Deaths According to Site of Ulcer}

Chief interest centres on gastric and duodenal perforations, which are discussed below. Perforations at other sites comprised : stomal, 90 cases (12 died); in Meckel's diverticula, 4 cases ( 1 died); oesophageal, 1 case (died); and site not stated, 425 cases (60 died).

The numbers of deaths from gastric and duodenal perforations in males and females are given in Table II. In both sexes the fatality rate for gastric perforation was much higher than for duodenal, and this was found to be true at all ages.

TABLE II

\begin{tabular}{|c|c|c|c|c|c|}
\hline & & & \multirow{2}{*}{$\begin{array}{l}\text { Total } \\
\text { Cases }\end{array}$} & \multicolumn{2}{|c|}{ Died } \\
\hline & & & & No. & $\%$ \\
\hline $\begin{array}{c}\text { Gastric (male) } \\
\begin{array}{c}\text { (female) } \\
\text { Duodenal (male) }\end{array} \\
\text { " } \quad \text { (female) }\end{array}$ & $\begin{array}{l}\because \\
\therefore \\
\cdots\end{array}$ & $\begin{array}{l}\cdots \\
\cdots \\
\cdots\end{array}$ & $\begin{array}{r}248 \\
71 \\
5,175 \\
378\end{array}$ & $\begin{array}{r}66 \\
20 \\
444 \\
50\end{array}$ & $\begin{array}{r}26 \cdot 6 \\
28 \cdot 2 \\
8 \cdot 7 \\
13 \cdot 2\end{array}$ \\
\hline
\end{tabular}

The fatality rate from gastric perforation was about the same in the two sexes ( $26.6 \%$ in males and $28.2 \%$ in females).

The fatality rate from duodenal perforation was materially lower in males $(8.7 \%)$ than in females $(13.2 \%)$, but much of the difference is attributable to the older ages at which women perforate. The male fatality rate rises to $10.1 \%$ when it is standardized on the age distribution of females, and the remaining difference between the sexes might well be a chance finding.

\section{Deaths by Delay in Treatment}

Information on the interval between perforation and operation was sought in the records of 4,206 patients and was found in 2,837 . The relation between delay in operation and outcome is shown in Fig. 9. The sharp rise in fatality with delay in operation accords with the general experience and needs no comment.

It will be seen from Fig. 9 that 79 patients were admitted to hospital moribund, in whom operation was not attempted. This group alone accounts for more than one-sixth of all deaths in the series. 


\section{Deaths by Season of the Year}

Fatality rates remain a little higher in the winter months (October-March) than in summer (April-September). The winter rate was $11.3 \%$ (363 deaths in 3,221 cases) as against the summer rate of $9.4 \%$ (292 deaths in 3,122 cases).

This difference between the winter and summer fatality rates appears small, but it does in fact conceal the pro-

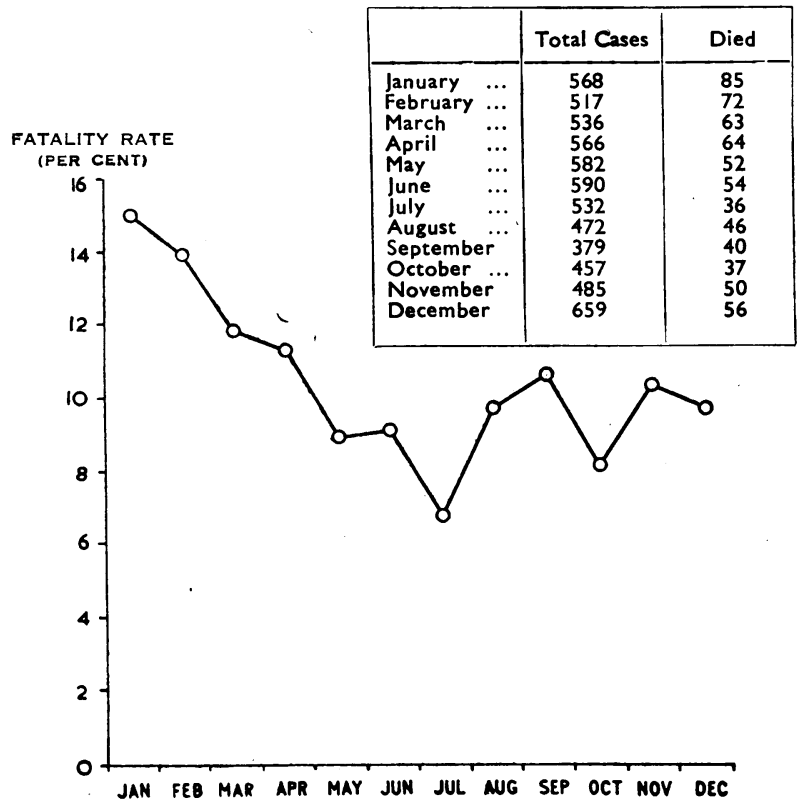

FIG. 10.-Fatality rate by months. Perforations, 4 counties, 1944-53.

nounced seasonal variation displayed in Fig. 10, where the fatality rates are shown for individual months. It will be seen that there is an abrupt rise in the fatality rate in January from the December level, followed by a gradual fall throughout February, March, and April. This pattern resembles the seasonal changes in deaths certified as due to respiratory diseases (Annual Reports for the RegistrarGeneral for Scotland), and pulmonary complications may well account for the seasonal changes in fatality from perforation.

\section{Summary}

The incidence of perforated peptic ulcer has been studied in an area of the West of Scotland with a population of over two million. The present report covers the period 1944-53 and brings up to date the previous report for 1924-43. The chief findings are:

1. The incidence of perforation has increased threefold between 1924 and 1953: The increase has been steadily progressive except for an anomalous high incidence during the war years 1941-2.

2. Perforation is much commoner in men than in women, but the sex ratio has fallen from 19:1 formerly to $12: 1$ latterly.

3. The average age at perforation continues to rise. It remains higher in women than in men, but by a margin which is narrowing.

4. Between the census years 1931 and 1951 the incidence of perforation increased at all ages. The increase was slight in youth, moderate in middle age, and great in old age.

5. Among adult males with peptic ulcer, between 1 and $2 \%$ perforate annually. A history of previous perforation does not appear to increase the risk of perforating again.
6. Perforation is relatively uncommon in August, September, and October, and is unduly common in December. These changes may be due to rest at the July holiday season, and to fatigue in December.

7. Perforation is least common on Sundays and becomes progressively commoner throughout the week, reaching a maximum incidence on Fridays. These changes may be due to rest and fatigue.

8. Perforation is relatively uncommon during the night. Its incidence increases to a minor peak at the end of the morning, to a major peak at the end of the afternoon, and again to a minor peak in the late evening. These changes may be due to rest and fatigue.

9. Pyloro-duodenal perforations outnumber gastric perforations in the ratio of $21: 1$ in men and $5: 1$ in women.

10. The overall fatality rate from perforation has fallen progressively from $25 \%$ in 1924 to $8 \%$ in 1953 .

11. The fatality rate increases rapidly with advancing age, is much higher in gastric than in pyloro-duodenal perforation, increases with delay in operation, and is seasonally high in January and the early spring.

My thanks are due to the boards of management, superintendents, surgeons, and records officers of the hospitals in the West of Scotland, whose co-operation, freely given, alone made this survey possible; to the Registrar-General for Scotland for providing annual estimates of population; and to Miss S. G. Murray and Mrs. M. Mackenzie for much secretarial help.

\section{REFERENCES}

Doll, R., and Jones, F. A. (1951). Spec. Rep. Ser. med. Res. Coun. (Lond.), No. 276

Illingworth, C. F. W., Scott, L. D. W., and Jamieson, R. A. (1944). British Medical Journal, 2, 617, 655 .

- - (1946). Ibid., 1, 787

Jamieson, R. A. (1947). Ibid., 2, 289.

The first Medical Records Exhibition was held in London on May 21, organized by the Association of Medical Records Officers. It illustrated current methods of keeping and storing records and of marshalling patients. At Woolwich Memorial Hospital the whole of a patient's notes are photographed on to a single negative. At University College Hospital, microfilming has been resorted to, radiographs included. Existing storage space can also be made to hold more folders by using mobile stacks of shelving to reduce the circulating area required in the record store, or lateral filing to increase the number of levels of shelving between floor and ceiling. At the Edgware General Hospital the out-patient cards are kept apart from the in-patient notes and destroyed after seven years; the in-patient notes are bound after one year and after 20-25 years destroyed, with the exception of summary sheets, a system that demands a high standard of summary writing. Surveys indicate that no patients return for the same condition after 15 years. Sound-recording facilities exhibited from the Hospital for Sick Children showed that dictation can now be recorded on disk machines in the typing room. Devices such as visible card-trays have been found to ease the task of selection and control of waiting-lists. A public health records exhibit featured a continuous health record kept from the antenatal period until school-leaving age. The Farnborough Hospital exhibit included a nightly ward return which not only served as a basis for bed statistics but contained a forecast of patient movements in the next 24 hours, this being used as a guide in dealing with applications for emergency admission. The value of graphs in the improved use of hospital accommodation was stressed on the King's College Hospital stand. Dr. N. M. Goodman delivered a lecture on "Records and Statistics of Cancer," stressing that systematic follow-up and analysis of records over many years were essential to medical progress. 